\title{
Partition property of pyrene onto synthetic membrane vesicles and the effects of natural organic matters
}

\section{AUTHOR(S):}

Ikeda, Kazuhiro; Shimizu, Yoshihisa; Matsui, Saburo; Oguri, Takuya; Sekida, Makoto; Kawata, Atsusi; Kusakabe, Taketoshi

\section{CITATION:}

Ikeda, Kazuhiro ...[et al]. Partition property of pyrene onto synthetic membrane vesicles and the effects of natural organic matters. KSCE Journal of Civil Engineering 2008, 12(2): 91-97

\section{ISSUE DATE:}

2008-03

URL:

http://hdl.handle.net/2433/123368

\section{RIGHT:}

Copyright (C) 2009 Springer; この論文は出版社版でありません。引用の 際には出版社版をご確認ご利用ください。; This is not the published version. Please cite only the published version. 
Partition Property of Pyrene onto Synthetic Membrane Vesicles and the Effects of Natural Organic Matters

Kazuhiro Ikeda*, Yoshihisa Shimizu**, Saburo Matsui***, Takuya Oguri****, Makoto Sekida****, Atsusi Kawata****, Taketoshi Kusakabe****

Abstract:

In this study, we investigated the partition property of pyrene onto cell membrane using synthetic membrane vesicles consisted of several phospholipids and the effect of natural organic matters (NOM) on the partition. Membrane fluidity and membrane phase affected partition coefficient $\left(P_{m w}\right)$ of pyrene onto the membrane. $P_{m w}$ was larger for the liposome in liquid crystalline phase $>$ in ripple phase $>$ in gel phase. Pyrene did not undergo the steric interfere in partition onto the membrane used in this study. Negative charge of the membrane did not affect $P_{m w}$ of pyrene.

Suwannee River Natural Organic Matter (NOM) and Nordic fulvic acid affected the partition of pyrene onto the TRANSIL ${ }^{\circledR}$ membrane. The reason was confirmed that NOM associated pyrene did not partition onto the membrane. Low molecular weigh fraction of SRNOM had strong effect on the partition as much as high molecular weigh fraction. From calorimetrical analysis, it was found that SRNOM did not affect the fluidity of the dimyristoylphosphatidylcholine (DMPC) membrane.

Keywords:

Pyrene, Polyaromatic Hydrocarbons (PAHs), Synthetic Membrane Vesicles, Fluidity, Partition Coefficient between Membrane and Water $\left(P_{m w}\right)$, Natural Organic Matter (NOM), $K_{o c}$

1. Introduction 
Pyrene is categorized into polyaromatic hydrocarbons (PAHs) and one of the typical contaminants in the natural water systems and water treatment plants. It is suspected to have adverse effects on the aquatic organisms, especially strongly with sunlight (International Programme on Chemical Safety, 1998). Therefore, great attention should be paid to maintain the sound ecosystems.

Pyrene is a hydrophobic organic compound, and it is considered to penetrate into the cell membrane by passive diffusion. Pyrene partition onto the cell membrane, which is quantified with partition coefficient $\left(P_{m w}\right)$, is very important with the reasons below.

One is that cell membrane is the target site for the baseline toxicity of hydrophobic organic compounds to the aquatic organisms (Escher and Hermens, 2002). Therefore $P_{m w}$ evaluates that toxicity of those pollutants.

Another is that $P_{m w}$ is a kinetic (toxicokinetic) parameter to determine the uptake rate of hydrophobic organic compounds into the body from water (Parsons and Opperhuizen, 1987). When bioconcentration or toxicity is estimated, $P_{m w}$ is critically important to simulate the distributions of hydrophobic organic compounds in the body. $P_{m w}$ is also significant in the field of biological treatment process of wastewater to access the sorptive removal onto the sludge or degradation capability of hydrophobic organic compounds.

$P_{m w}$ is often substituted by $n$-octanol /water partition coefficient $\left(K_{o w}\right)$. Cell membrane is, however, inherently different from octanol in the physicochemical property (Gobas et al., 1988). Cell membrane has steric structure called lipid bilayer with surface charge from twitter ions of lipids which consist of cell membrane. Therefore, hydrophobic organic compounds may interact electrostatically with cell membrane and/or undergo the interference by rigid structure when they partition into the lipid phase in cell membrane, although they do not in the case of octanol which is a bulk solvent.

Natural organic matter (NOM) can take a large role when aquatic organism or activated sludge uptakes pyrene. Hydrophobic organic compounds easily sorb to the NOM and aquatic organism has 
been believed to uptake only freely dissolved fraction, because the fraction associated with NOM can not pass the cell membrane. Several researchers (Haitzer et al., 1999; Mccarthy et al., 1994; Kukkonen and Oikari, 1991) reported NOM decreased the bioconcentration or toxicity of hydrophobic organic compounds, but they have some questions due to the uncertainty of bioassay (Haitzer et al., 2001). Then we need to prove the assumption that NOM associates can not be taken into the cell membrane.

In this study, we investigated the partition property of pyrene onto cell membrane using synthetic membrane vesicles. The lipids which consist of actual organisms are different for the kind of organisms and organs and the physicochemical property of the membrane is varied. Therefore we focused the effects of the lipid component, which affects the fluidity and surface charge of membrane, on the partition of pyrene. This may contribute to the estimation of pyrene uptake by the variety of aquatic organisms for the future. We also demonstrated the effects of NOM on pyrene partition onto cell membrane. NOMs are ubiquitous and have different structures and properties for their origins. We used several NOMs and investigated how the NOM property impacted their effects.

\section{Materials and Methods}

\subsection{Chemicals and quantification}

Pyrene is selected as a target chemical and other three PAHs are selected for comparison in the investigation of partition property of pyrene. Pyrene (98\%) as 4-rings $\mathrm{PAH}$, and fluorene (95\%), phenantherene (95\%) and anthracene (98\%), as 3-rings PAHs, were purchased from Wako (Japan). PAHs concentrations were basically measured by fluorescence (pyrene; ex. $335 \mathrm{~nm}$, em.371 nm, fluorene; ex.264 nm, em.301 nm, phenantherene; ex.294 nm, em.363 nm, and anthracene; ex.250 nm, em.379 nm). Measured fluorescence was corrected for the inner filter effect according to the method developed by Shimizu (Shimizu and Liljestrand, 1991). Pure water (specific resistance $>18 \mathrm{M} \Omega \mathrm{cm}$ ) 
was used by processing distilled water with epw-200 (Advantec, Japan) water purification system equipped with ion exchange column and filtration column. Other chemicals used were higher grade than reagent grade.

2.2 Effects of the lipid component (membrane fluidity) on the partition of pyrene onto cell membrane

\subsubsection{Preparation of liposome solution}

For this study, we made five kinds of liposome, as synthetic membrane vesicles, using five phospholipids purchased from Sigma (Japan). Dilauroylphosphatidylcholine (DLPC: C12), dimyristoylphosphatidylcholine (DMPC: C14), dipalmitoylphosphatidylcholine (DPPC: C16), distearoylphosphatidylcholine (DSPC: C18) and diarachidoylphosphatidylcholine (DAPC: C20), which are listed in descending order of acyl chain length, were selected and synthesized into five liposomes which had different fluidity of membranes. DLPC liposome has the highest fluidity and DAPC liposome has the lowest.

The liposomes were synthesized with evaporation method developed by Moscho (Moscho et al., 1996) with slight modification by us and refined with rapid extrusion to lower the polydispersity (Mayer et al., 1986). First, the lipid solution in chloroform and $10 \mathrm{mM}$ phosphate buffer (pH 7) were added in round-bottom flask. Chloroform was then removed with rotary evaporator by two steps of decompression. The liposome solution was left in the phosphate buffer and flowed by rapid extrusion with $1.2 \mu \mathrm{m}$ polycarbonate filter in water bath at higher than $10{ }^{\circ} \mathrm{C}$ of their main phase transition temperatures. The resulting liposome diameters were around $1 \mu \mathrm{m}$.

\subsubsection{Measurement of partition coefficients of PAHs onto the liposomes}

Batch sorption experiments were conducted for measurement of partition coefficient $\left(P_{m w}\right)$ of 
PAHs onto the varieties of liposomes. PAHs concentrations were set below their $50 \%$ solubility.

PAHs and liposomes were incubated with rotary shaker in the $15 \mathrm{~mL}$ test tube for 24 hour at $25^{\circ} \mathrm{C}$ in $10 \mathrm{mM}$ phosphate buffer (pH7), followed by quantification of freely dissolved PAHs concentration. Liposomes as sobent were prepared in five different concentrations. $P_{m w}$ was calculated by the next equation (Takahashi et al., 2003).

$C_{0} / C=1+P_{m w}[$ lip $]$

In equation (1), $C_{0}$ is freely dissolved PAHs concentration without liposome, $C$ is freely dissolved PAHs concentration with liposome and [lip] is liposome (synthetic membrane vesicle) concentration. Freely dissolved concentration could not be measured directly, because the separation of liposome from the aqueous phase was practically impossible. Then we used fluorescence enhancement method we developed before (Takahashi et al., 2003). Briefly, PAHs associated with liposome emit a strong fluorescence. Aqueous phase fluorescence was the sum from freely dissolved PAH and liposome associated PAH. After sorption experiment reached equilibrium, we can adjust the aqueous liposome concentration by centrifugation. The solution fluorescence measured with Shimadzu (Japan) RF-5000 spectrofluorometer, was plotted to liposome concentrations measured by absorbance at 350 $\mathrm{nm}$ (UV2500PC, Shimadzu, Japan). The fluorescence correlates the aqueous liposome concentration and we can get the fluorescence from freely dissolved PAHs as the intercept of liner correlation. This method has the advantage that plastic devices were not used and lower the error from soptive loss to those, which is often problem for using hydrophobic organic compounds.

2.3 Effects of the lipid component (membrane surface charge) on the partition of pyrene onto cell membrane 


\subsubsection{Synthetic membrane vesicle selection}

To evaluate the effects of membrane surface charge on the partition of pyrene onto cell membrane, we prepared both negative charged and neutral charged synthetic membrane vesicles. Manufacture synthesized membrane vesicles named as TRANSIL $^{\circledR}$ (Nimubus biotechnology, Germany) were purchased for this study. TRANSIL ${ }^{\circledR}$ has silica beads (specific gravity $>1$ ) in its inner aqueous phase and is, therefore, easy to separate from the aqueous phase by centrifugation (Loidl-Stahlhofen et al., 2001) For sorption experiment, this is superior to liposome due to easy measurement of freely dissolved sorbate, although this is more expensive than liposome which can be synthesized in the laboratory. In this study, we used neutral charged TRANSIL $^{\circledR}$ consisted of egg yolk phosphatidylcholine (EPC-TRANSIL ${ }^{\circledR}$ ) and negative charged TRANSIL ${ }^{\circledR}$ consisted of $80 \%$ EPC $^{2}$ and 20\% palmitoyl-oleoylphosphatidylserine (POPS-TRANSIL ${ }^{\circledR}$ ).

\subsubsection{Measurement of partition coefficient $\left(P_{m w}\right)$ of PAHs onto the TRANSIL ${ }^{\circledR}$}

Batch sorption experiments were conducted basically in same way as section 2.2.2. In this experiment, freely dissolved PAHs concentration was measured after perfectly removing TRANSIL ${ }^{\circledR}$ from the aqueous phase by centrifugation.

2.4 Effects of NOM on pyrene partition onto cell membrane.

\subsubsection{NOMs}

Suwannee River natural organic matter (SRNOM) obtained from International Humic Substances Society (IHSS) was used for this study. This NOM has been often used in the environmental researches as representative NOM of colored water river. Nordic fulvic acid (NFA) also was obtained from IHSS and used. SRNOM and NFA were extracted from different flesh waters and have different physicochemical properties (IHSS, 2007). 
To use NOM of definitely different property, we fractionated SRNOM based on molecular weight using ultrafiltration membrane device (Pellicon2 equipped with regenerated cellulose membrane of molecular weight cut off 1,000 Da, Millipore, Japan). SRNOM solution (400 mgC/L) in $20 \mathrm{mM}$ phosphate buffer ( $\mathrm{pH} 7.2)$ was processed in transmembrane pressure; $50 \mathrm{psi}$ and retentate flow rate; $1.8 \mathrm{~L} / \mathrm{min}$. The resulted retentate was high molecular weight fraction named as HMNOM and the permeate was low molecular weight fraction named as LMNOM.

\subsubsection{Measurement of partition coefficient $\left(P_{m w}\right)$ of pyrene onto the TRANSIL ${ }^{\circledR}$ with NOM}

In order to evaluate the effects of NOM on pyrene partition onto cell membrane, $P_{m w}$ was measured with the presence of NOM in different concentrations. In this case, the aqueous phase and/or membrane phase have both of freely dissolved fraction and NOM associated fraction. Then, $P_{m w}$ means distribution ratio of pyrene between the aqueous phase and membrane phase. Therefore, if NOM associate does not partition onto the membrane, $P_{m w}$ should be lower with NOM than that without NOM.

In this study, EPC-TRANSIL ${ }^{\circledR}$ was used as synthetic membrane vesicle. Batch sorption experiments were conducted basically in same way as in section 2.3.2, although the concentration of phosphate buffer was changed to $20 \mathrm{mM}$ and $\mathrm{pH}$ was changed to 7.2 . This time $P_{m w}$ was calculated by equation (1) but $C_{o}$ means the aqueous PAHs concentration without liposome and $C$ means the one with liposome.

Aqueous pyrene concentration including freely dissolved fraction and NOM associated fraction was quantified with Waters 600E HPLC (Japan) equipped with Waters 474 scanning fluorescence detector (Japan) using HS Discovery C18 column (4.6 x $150 \mathrm{~mm} 5 \mu \mathrm{m}$, SPELCO, Japan) in the isocratic condition (flow rate: $1.0 \mathrm{~mL} / \mathrm{min}$, elluent: $80 \%$ as volume of acetonitrile and $20 \%$ as volume of water). We previously confirmed that when pyrene concentrations were identical in the solutions, the analytical signal corresponding to pyrene were identical in regardless of the presence 
of NOM under the NOM concentration in this study.

2.5 Measurement of sorption coefficient $\left(K_{o c}\right)$ of pyrene to NOM

In order to mechanistically evaluate the effects of NOM on the partition of pyrene onto the synthetic membrane vesicle, sorption coefficient $\left(K_{o c}\right)$ of pyrene to NOM was measured. Batch sorption experiments were conducted basically in same way as in section 2.4.2. $K_{o c}$ was calculated by fluorescence quenching method (Gauthier et al., 1986). Solution fluorescence was quantified with Hitachi F-4000 spectrofluorometer (Japan) and absorbance with Shimadzu UV-2500PC (Japan).

2.6 Membrane fluidity measurement

The fluidity of the membrane dramatically increases above main phase transition temperature $\left(T_{m}\right)$, where phase change occurs from gel phase to liquid crystalline phase. $T_{m}$ is determined by the strength of lipids interaction within the membrane and high fluidity membrane has low $T_{m}$ (Blume, 1983).

$T_{m}$ of the concerned membrane is expected to be changed if some forces change its fluidity. We tried to test hypothesis that NOM interacts the membrane and changes the fluidity. SRNOM and the TRANSIL $^{\circledR}$ which was consisted of dimyristoylphosphatidylcholine (DMPC-TRANSIL ${ }^{\circledR}$ ) were mixed for 24 hours at $25^{\circ} \mathrm{C}$ in $20 \mathrm{mM}$ phosphate buffer (pH7.2). Then the solution was calorimetrically analyzed with Shimazdu DSC-60 differential scanning calorimeter (Japan) in order to measure endothermic energy in the phase transition and determine $T_{m}$. At DSC analysis, heating rate was $2.0^{\circ} \mathrm{C} / \mathrm{min}$ and reference pan was filled with phosphate buffer. The effect of NOM on the fluidity was evaluated by comparing the results with NOM and without NOM. 
3. Results and Discussions

3.1 Partition property of pyrene onto synthetic membrane vesicles

Table 1 summarized $P_{m w}$ of PAHs onto the varieties of the liposomes with different acyl chains.

Correlation coefficients and intercepts in equation (1) for calculation of $P_{m w}$ were listed together. Acceptable correlation coefficients $\left(\mathrm{R}^{2}>0.68\right)$ mean the determination of $P_{m w}$ was acceptable. Fluorescence enhancement method had been applied to the liposome in gel phase before (Takahashi et al., 2003) for the first time. The applicability of this method to the liposome in the liquid crystalline and ripple phase was also confirmed in this research.

The effect of the acyl chain length of the phospholipids in the liposome on $P_{m w}$ of pyrene was shown in Fig.1. $P_{m w}$ increased with decrease of the acyl chain length, when the fluidity of the liposome membrane increased. DAPC liposome, DSPC liposome and DPPC liposome are in gel phase in $25{ }^{\circ} \mathrm{C}$ (the sorption experiment condition). On the other hand, DMPC liposome is in ripple phase and DLPC liposome is liquid crystalline phase. The fluidity of liposome membarene was increased dramatically with change of the phase from gel to ripple and ripple to liquid crystalline (Gennis, 1989) and $P_{m w}$ was increased in the same way. It was found that fluidity and phase of the membrane have large effects on the partition of pyrene to the membrane.

The $\log P_{m w}$ of PAHs onto DPPC liposome (gel phase) and DLPC liposome (liquid crystalline phase) was plotted to their $\log K_{o \mathrm{w}}$ in Fig.2. $\log P_{m w}$ has good correlation to $\log K_{o w}$ for both liposomes $\left(\mathrm{R}^{2}=0.84\right.$ for DPPC liposome and $\mathrm{R}^{2}=0.94$ for DLPC liposome). This means the driving forces of partition is same between $P_{m w}$ and $K_{o w} . K_{o w}$ is the index to evaluate the hydrophobicity. Then, these PAHs may partition onto the membrane basically due to the hydrophobic interaction. If there is the interference originated from the rigid structure of the membrane and the size of PAH molecule in the penetration of PAHs into the membranes, the relation of $\log P_{m w}$ and $\log K_{o w}$ must be 
convex upward because bulk solvent octanol does not exert that interference for $K_{o w}$ (Gobas et al., 1988). However, that relation was not found for both liposomes of gel phase and liquid crystalline phase. The steric interference does not exist in the partition of pyrene onto these membranes. From Fig.2, $P_{m w}$ of 3-4 ring PAHs might be estimated from $K_{o w}$. However, precise estimation was not expected because it was found that $P_{m w}$ of phenanthrene which has higher $K_{o w}$ was lower than anthracene which has lower $K_{o w} . P_{m w}$ should be measured directly.

Table 2 summarized $P_{m w}$ of PAHs for EPC-TRANSIL ${ }^{\circledR}$ and POPS-TRANSIL ${ }^{\circledR} \cdot \log P_{m w}$ was also plotted to $\log K_{o w}$ in Fig.3. Good correlation was shown between $\log P_{m w}$ for negative charged EPC-TRANSIL ${ }^{\circledR}$ and for neutral charged EPC-TRANSIL ${ }^{\circledR}$. This meant that electrostatic interaction was little important in partition of PAHs onto the membrane. $P_{m w}$ of PAHs for EPC-TRANSIL ${ }^{\circledR}$ was not perfectly identical to $P_{m w}$ for POPS-TRANSIL ${ }^{\circledR}$. This is because not only surface charge but also acy chain composition was different between EPC-TRANSIL ${ }^{\circledR}$ and POPS-TRANSIL ${ }^{\circledR}$, although both membranes are in the gel phase.

3.2 Effects of NOM on pyrene partition onto the synthetic membrane vesicles

Table 3 summarized $K_{o c}$ of pyrene to SRNOM and NFA. Pyrene was found to sorb to SRNOM almost as much as to NFA. The ratio of freely dissolved fraction when NOM exists is calculated by the next equation (Mccarthy et al., 1994).

$($ ratio of freely dissolved fraction $)=1 /\left(1+K_{o c}[N O M]\right)$

When SRNOM concentration is $40 \mathrm{mgC} / \mathrm{L}$, ratio of freely dissolved fraction is 0.7 , which means $30 \%$ of pyrene was associated to SRNOM. Alhough $K_{o c}$ of pyrene may be varied with the varieties of NOMs (Gauthier et al., 1987) and this result may not directly be able to apply to the other water 
system than Suwannee River, NOM associated pyrene should be took into account to control pyrene pollution in the natural water with high concentration of NOM like peatland water.

Fig.4 showed $P_{m w}$ of pyrene onto EPC-TRANSIL ${ }^{\circledR}$ with the presence of SRNOM and NFA. For both NOM, $P_{m w}$ dramatically decreased as the concentration of NOM increased. These NOMs decrease the partition of pyrene on the membrane, which meant that the uptake of pyrene by aquatic organisms might decreased significantly with NOM.

If it is assumed that NOM associated pyrene can not partition onto the membrane, $P_{m w}$ was calculated by the next equation (Gauthier et al., 1987).

$P_{m w}(x) / P_{m w}(0)=1 /\left(1+K_{o c}[N O M]\right)$

In equation (3), $P_{m w}(x)$ is $P_{m w}$ when the concentration of NOM is $x . P_{m w}$, which was estimated from this equation assigned by measured $K_{o c}$, was shown in Fig.4. Estimated $P_{m w}$ satisfactorily fitted in the measured $P_{m w}$. This meant that only freely dissolved pyrene could partition onto the membrane.

It was considered that the NOM associated pyrene could not partition onto the membrane because the size of associated pyrene became bigger than pyrene molecule, so that the steric interfere was originated and/or associated pyrene had higher hydrophilicity, therefore it lost driving force, hydrophobic interaction, to partition onto the membrane.

Fig.5 showed $P_{m w}$ of pyrene onto EPC-TRANSIL ${ }^{\circledR}$ with the presence of HMNOM and LMNOM, respectively, which are the fraction of SRNOM separated by molecular weight cut off 1,000 Da UF membrane. It was found that both NOMs decreased $P_{m w}$ of pyrene to almost same extent. From this result, the relatively low molecular weight NOM may be also important role in the fate of pyrene in natural waters.

Fig.6 showed the NOM effect on the main phase transition temperature of DMPC-TRANSIL ${ }^{\circledR}$. Endothermic peaks, indicating the phase transition, was found at the same temperature. It meant that 
10 and $40 \mathrm{mg} / \mathrm{L}$ of SRNOM did not change $T_{m}$ at all. There was no evidence that SRNOM changed the fluidity of the membrane in DMPC-TRANSIL ${ }^{\circledR}$. We had previously conducted the sorption experiment of SRNON to EPC-TRANSIL ${ }^{\circledR}$ and had found that NOM did not sorb onto EPC-TRANSIL ${ }^{\circledR}$ (Data not shown). We did not confirm for DMPC-TRANSIL ${ }^{\circledR}$ used in this study, although SRNOM was not considered to sorb to DMPC-TRANSIL ${ }^{\circledR}$.

\section{Conclusions}

In this study, we investigated the partition property of pyrene onto cell membrane using synthetic membrane vesicles. The membrane fluidity and the membrane phase affected $P_{m w}$ of pyrene. $P_{m w}$ for DLPC liposome in liquid crystalline phase was highest and $P_{m w}$ for DMPC liposome in ripple phase was the next and $P_{m w}$ for DPPC, DSPC and DAPC liposome in gel phase was low. Pyrene did not undergo the steric interfere in partition onto the membrane used in this study. Negative charge of the membrane did not affect $P_{m w}$ of pyrene. These results will contribute the estimation of pyrene uptake by varieties of aqueous organisms which have many types of the membranes.

We also demonstrated the effects of NOM on pyrene partition onto cell membrane. SRNOM and NFA affected the partition of pyrene onto the TRANSIL ${ }^{\circledR}$ membrane. The reason was found that NOM associated pyrene did not partition onto the membrane. From calorimetrically analysis, it was found that SRNOM did not effect the fluidity of the DMPC membrane. These results suggest that the NOM associated pyrene was not toxic but not biodegradable and moves to the other environment like sediment from the natural water body. Therefore the degradability of the associates and the toxicity to the sediment organisms like soileater is critically considered and necessary to be investigated for the control of pyrene pollution.

In this study, we used pyrene, one of non-polar hydrophobic organic compounds. Hydroxylpyrene is one of the pyrene metabolites and its interaction to the membrane is considered to be different 
from pyrene because electrostatic interaction is expected in partition onto the membrane and sorption to NOM. In the future we will take up hydrophobic organic compound with hydrophilic functional groups. 
Reference

Blume, A. (1983). "Apparent molar heat capacities of phospholipids in aqueous dispersion.Effects of chain length and head group structure." Biochemistry, Vol.22, pp.5436-5442.

Escher, B. I. and Hermens, J. L. M. (2002) "Modes of action in ecotoxycology: their role in body burdens, species sensitivity, QSARs, and mixture effects.” Environmental Science \& Technology, Vol.36, pp.4201-4217.

Gauthier, T.D., Shane, E.C., Guerin, W.F., Seitz, W.R. and Grant, C.L. (1986). "Fluorescence quenching method for determining equilibrium constants for polycyclic hydrocarbons binding to dissolved humic materials." Environ. Sci. Technol. Vol.20, pp.1162-1166

Gauthier, T.D., Seitz, W.R. and Grant, C.L. (1987). "Effects of structural and compositional variations of dissolved humic materials on pyrene $K_{o c}$ Values." Environ. Sci. Technol. Vol.21, No.3, pp.243-248.

Gennis, R.B. (1989). Biomembrane -Molecular Structure and Function, Springer-Verlag, New York

Gobas, F.A.P.C., Lahittete, J.M., Garofalo, G. and Shiu, W.Y. (1988). “A novel method for measuring membrane-water partition coefficients of hydrophobic organic chemicals: comparison with 1-octanol-water partitioning.” Journal of Pharmaceutical Sciences, Vol.77, No.3, pp.265-272.

Haitzer, M., Hoss, S., Traunspurger, W. and Steinberg, C. (1999). "Relationship between concentration of dissolved organic matter (DOM) and the effect of DOM on the bioconcentration of 
benzo[a]pyrene.” Aquatic Toxicology, Vol.45, pp.147-158.

Haitzer, M., Akkanen, J., Steinberg, C. and Kukkonen, J.V.K (2001). "No enhancement in bioconcentration of organic contaminants by low levels of DOM." Chemosphere, Vol.44, pp.165-171

Hansch, C. and Fujita, T. (1964). " $\rho-\sigma-\pi$ analysis. A method for the correlation of biological activity and chemical structure." J. Am. Chem.Soc., Vol.86, 1616-1626

Hansch, C.L. (1979). Substitute Constants for Correlation Analysis in Chemistry and Biology, John Wiley \& Sons, New Jersey

International Humic Substances Society (2007), http://www.ihss.gatech.edu/.

International Programme on Chemical Safety (1998). Environmental Health Criteria 202 Selected Non-Heterocyclic Policuclic Hydrocarbons

Kenega, E.E. and Goring, C.A.I (1980). Aquatic Toxicology, ASTM, STP707

Kukkonen, J. and Oikari, A. (1991). "Bioavailability of organic pollutants in boreal waters with varying levels of dissolved organic material." Water Research, Vol.25, pp.455-463.

Loidl-Stahlhofen, A., Schmitt, J., Noller, J., Hartmann, T., Brodowsky, H., Schmitt, W. and Keldenich, J. (2001) "Solid-supported biomolecules on modified silica surfaces - a tool for fast physicochemical characterization and high-throughput screening." Advanced Materials, Vol.13, pp.1829-1834. 
Mayer, L.D., Hope, M.J., Cullis, P.R. (1986) "Vesicle of variable sizes produced by a rapid extrusion procedure.” Biochimica et Biophisica Acta, vol.858, pp.161-168.

Mccarthy, J. F., Strong-Gunderson, J. and Palumbo, A. V. (1994) "The significance of interactions of humic substances and organisms in the environment." Humic Substances in the Global Environment and Implications on Human Health, pp.981-996.

Moscho, A., Orwer, O., Chiu, D.T., Modi, B.P. and Zare, R.N. (1996) "Rapid preparation of giant unilamellar vesicles.” Proc. Natul. Acad. Sci., Vol.93, pp.11443-11447

Parsons, J.R. and Opperhuizen, A. (1987). "Influence of membrane permeation on biodegradation of hydrophobic compounds." Chemosphere, Vol.16, No.6, pp.1361-1370.

Shimizu, Y. and Liljestrand, H.M. (1991). "Sorption of polycyclic aromatic hydrocarbons onto natural solids: Determination by fluorescence quenching method." Wat Sci Technol. Vol.23, pp.427-436.

Takahashi, J., Shimizu, Y., Matsubara, J., Ikeda, K. and Matsui, S. (2003). "The sorption of PAHs into liposome (artificial cell membrane) for evaluating their bio-accumulation." Proceedings of the $4^{\text {th }}$ IWA Specialized Conference on Assessment and Control of Hazardous Substances in Water ECOHAZARD 2003 -, International Water Association, Aachen, Germany, pp.80/1-80/6 
Table $1 P_{m w}$ of PAHs onto the liposome of different acyl chain phospholipids

\begin{tabular}{|c|c|c|c|c|c|c|c|}
\hline \multirow[t]{5}{*}{$\mathrm{PAHs}$} & \multirow[t]{5}{*}{$\log K_{o w}$} & \multicolumn{6}{|c|}{$P_{m w}(\mathrm{~L} / \mathrm{kgC})^{(\mathrm{a})}$} \\
\hline & & $\begin{array}{l}\text { lipid of } \\
\text { liposome }\end{array}$ & DLPC & DMPC & DPPC & DSPC & DAPC \\
\hline & & $\begin{array}{c}\text { number of } \\
\text { acyl chain carbon }\end{array}$ & 12 & 14 & 16 & 18 & 20 \\
\hline & & $T_{m}^{(b)}$ & 0 & 23 & 43 & 55 & 64 \\
\hline & & $\begin{array}{c}\text { membrane } \\
\text { phase at } 25^{\circ} \mathrm{C}\end{array}$ & $\begin{array}{c}\text { liquid } \\
\text { crystalline }\end{array}$ & ripple & gel & gel & gel \\
\hline pyrene & $4.88^{(c)}$ & & $\begin{array}{l}5.4 \times 10^{5} \\
(1.8) \\
(0.72)\end{array}$ & $\begin{array}{c}1.4 \times 10^{5} \\
(2.2) \\
(0.68)\end{array}$ & $\begin{array}{c}3.8 \times 10^{4} \\
(0.95) \\
(0.99)\end{array}$ & $\begin{array}{l}2.0 \times 10^{4} \\
(1.0) \\
(0.98)\end{array}$ & $\begin{array}{l}1.5 \times 10^{4} \\
(0.92) \\
(0.75)\end{array}$ \\
\hline phenanthrene & $4.52^{(\mathrm{d})}$ & & $\begin{array}{c}8.9 \times 10^{4} \\
(0.98) \\
(0.99)\end{array}$ & & $\begin{array}{c}7.8 \times 10^{3} \\
(1.0) \\
(0.97)\end{array}$ & & \\
\hline anthracene & $4.34^{(\mathrm{d})}$ & & $\begin{array}{c}8.7 \times 10^{4} \\
(1.0) \\
(0.96)\end{array}$ & & $\begin{array}{c}1.1 \times 10^{4} \\
(0.94) \\
(0.94)\end{array}$ & & \\
\hline fluorene & $4.18^{(\mathrm{e})}$ & & $\begin{array}{c}3.0 \times 10^{4} \\
(1.0) \\
(0.95)\end{array}$ & & $\begin{array}{c}3.1 \times 10^{3} \\
(0.96) \\
(0.80)\end{array}$ & & \\
\hline
\end{tabular}

(a) In the column, the first line is $P_{m w}$, the second and the third are the intercept and $\mathrm{R}^{2}$, respectively, for fitted curve corresponding to the equation (1).

(b) Gennis (1989).

(c) Hansch (1979).

(d) Kenega and Goring (1980).

(e) Hansch and Fujita (1964). 


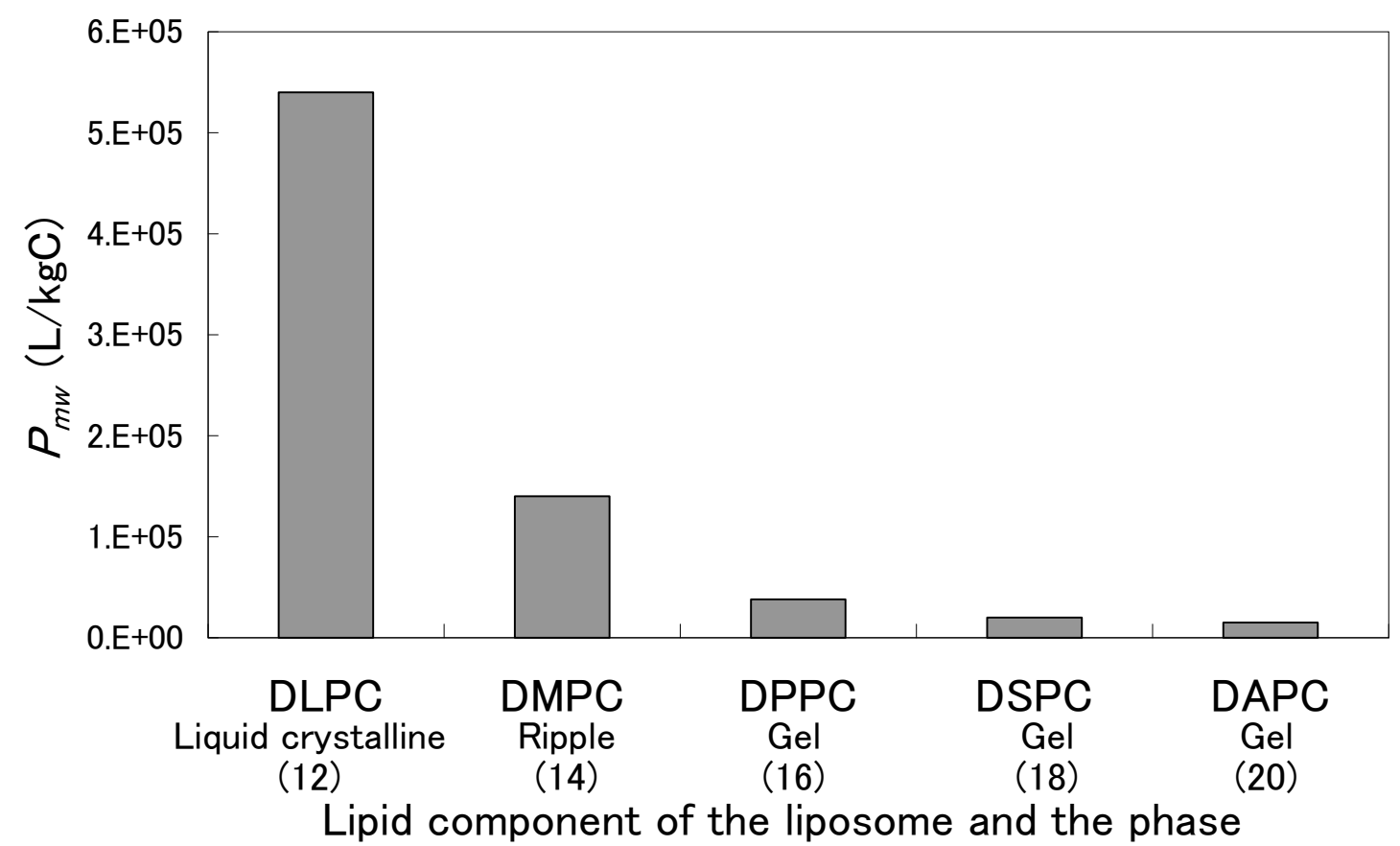

Fig.1 The effect of the fluidity of the membrane on $P_{m w}$ of Pyrene

The values in parenthesis indicate the number of chain carbon. 


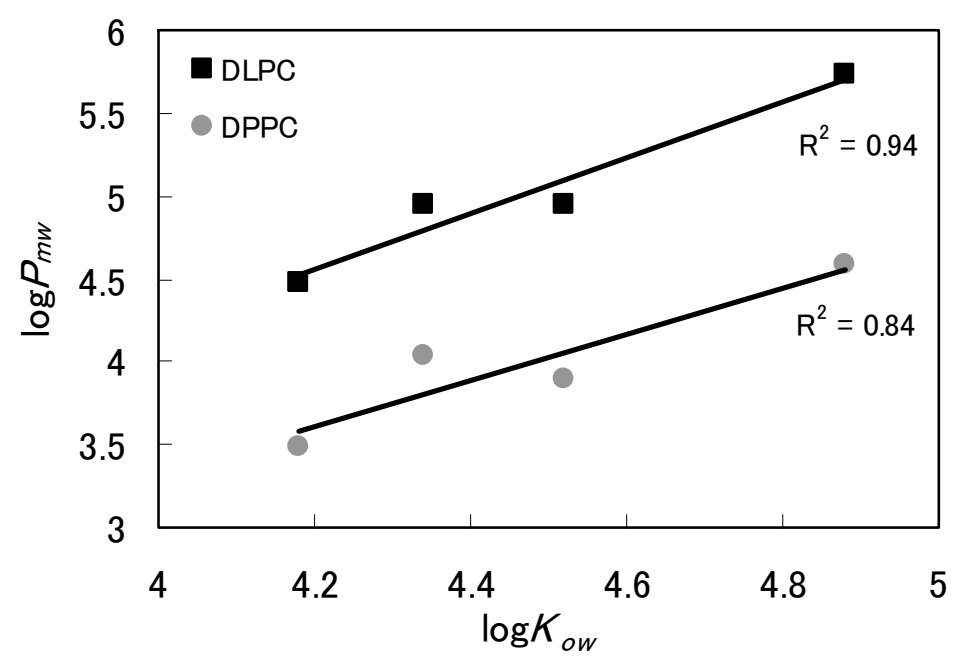

Fig.2 The correlation between $\log P_{m w}$ and $\log K_{o w}$ 
Table $2 P_{m w}$ of PAHs onto EPC-TRANSIL ${ }^{\circledR}$ and POPS-TRANSIL ${ }^{\circledR}$

\begin{tabular}{ccc}
\hline PAHs & EPC-TRANSIL $^{\circledR}$ & POPS-TRANSIL $^{\circledR}$ \\
\hline fluorene & $2.8 \times 10^{4}$ & $2.2 \times 10^{4}$ \\
phenanthrene & $9.4 \times 10^{4}$ & $6.1 \times 10^{4}$ \\
anthracene & $1.2 \times 10^{5}$ & $9.1 \times 10^{5}$ \\
pyrene & $6.7 \times 10^{5}$ & $5.9 \times 10^{5}$ \\
\hline
\end{tabular}




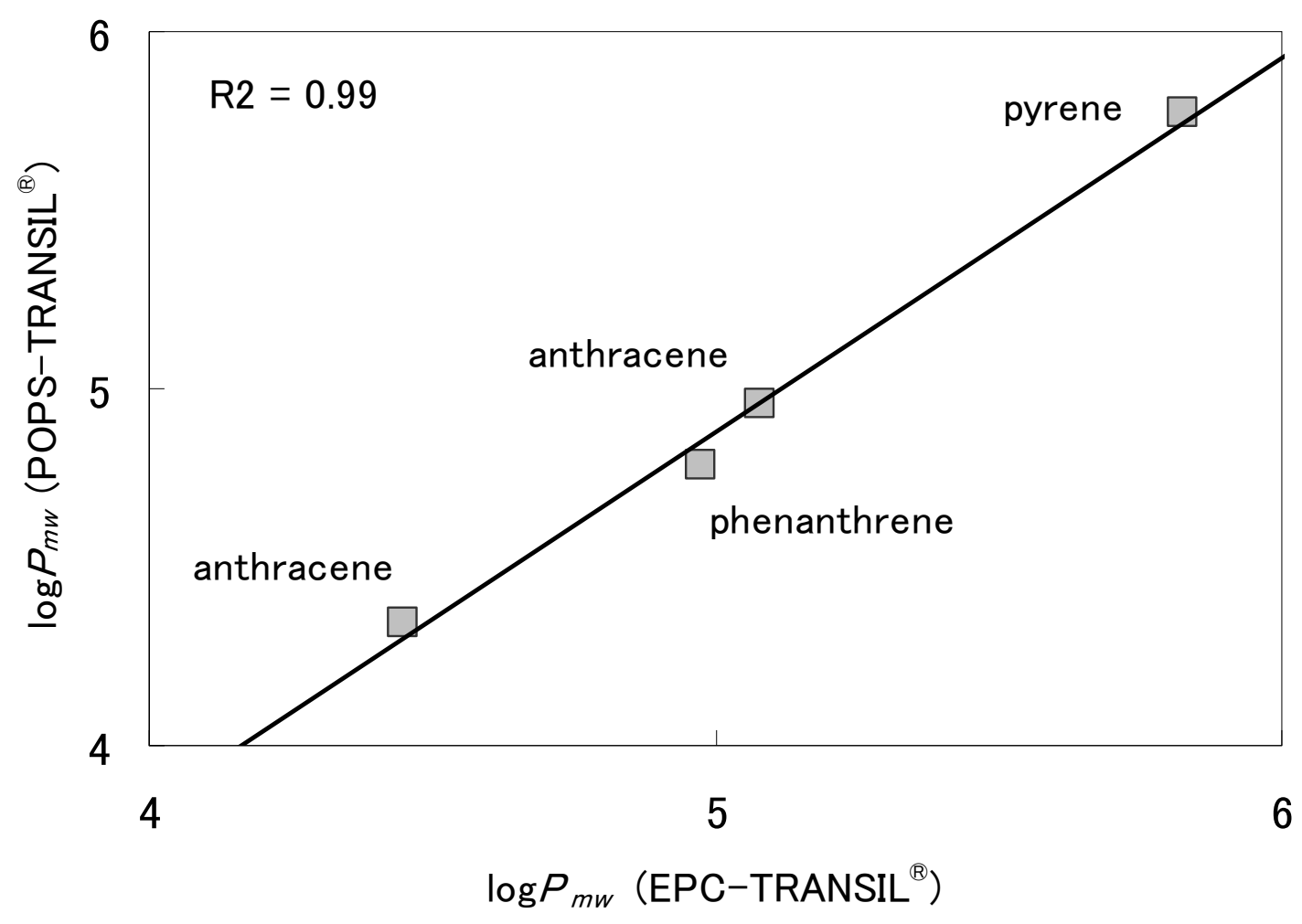

Fig.3 Correlation between $P_{m w}$ for POPS-TRANSIL ${ }^{\circledR}$ and EPC-TRANSIL ${ }^{\circledR}$ 
Table $3 K_{o c}$ of pyrene to NOMs

\begin{tabular}{ccc}
\hline NOM & SRNOM & NFA \\
\hline$K_{o c}$ & $1.7 \times 10^{4}$ & $1.8 \times 10^{4}$ \\
\hline
\end{tabular}



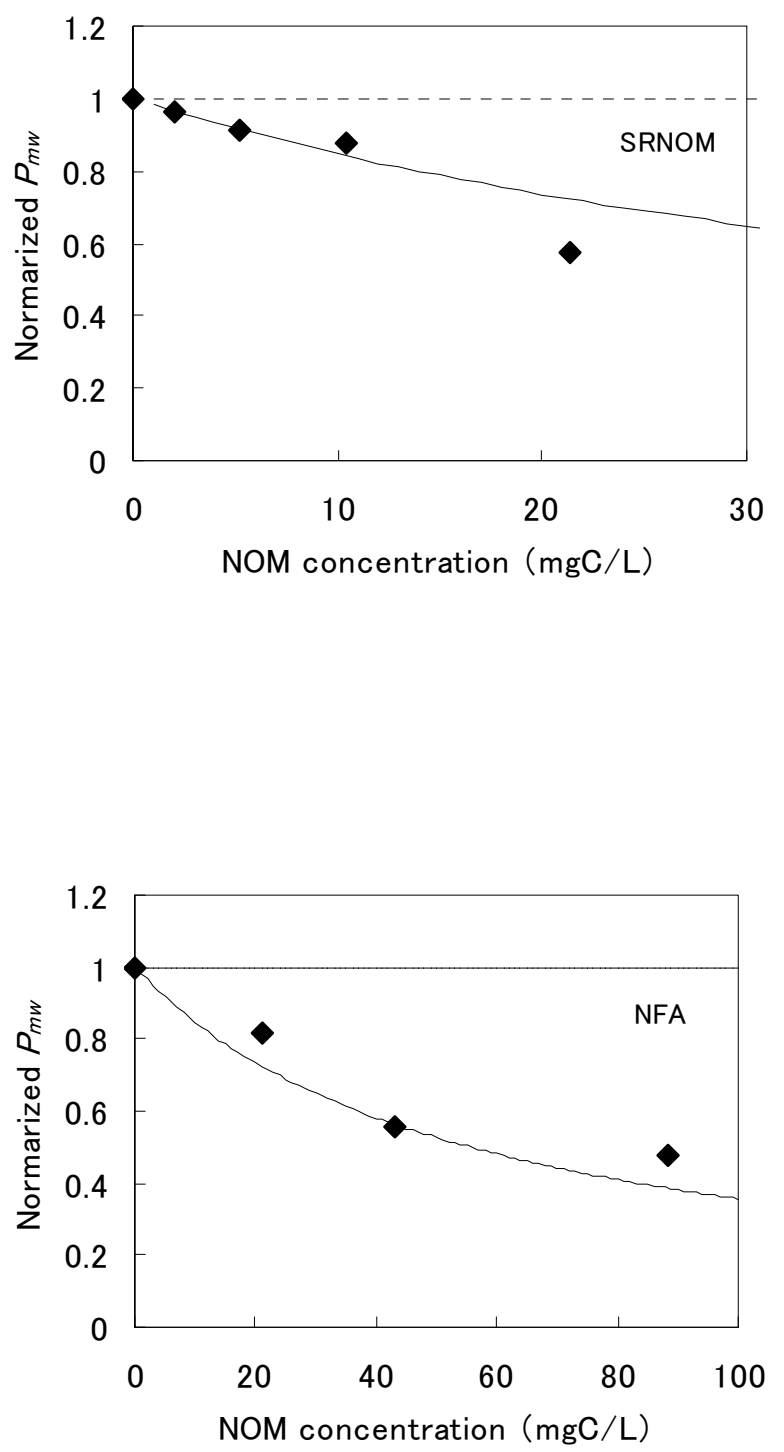

Fig.4 The effect of NOM on $P_{m w}$ of pyrene onto EPC-TRANSIL ${ }^{\circledR}$

Plots are measuered $P_{m w}$, the solid lines are estimated from equation (3) substituted by measured $K_{o c}$. 

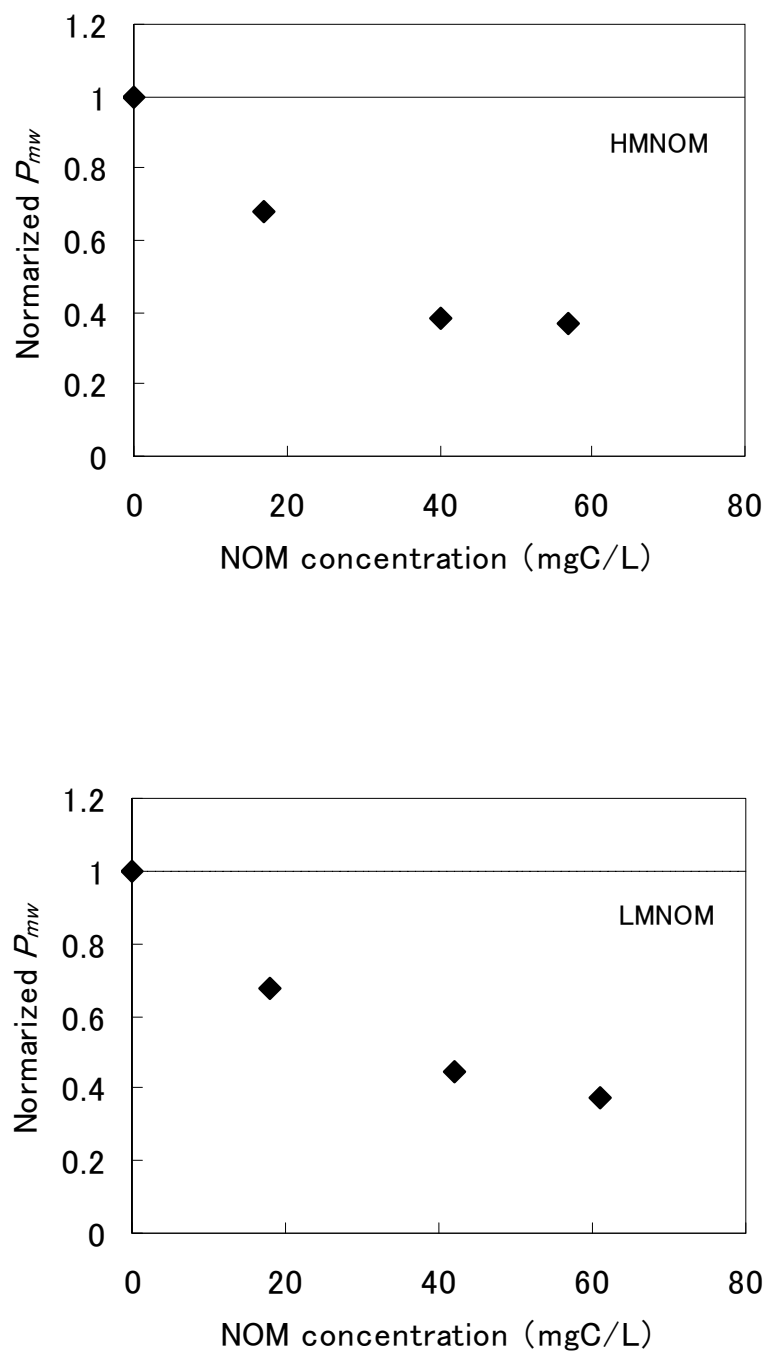

Fig.5 The effect of high molecular weight NOM and low molecular weight NOM on $P_{m w}$ of pyrene onto EPC-TRANSIL ${ }^{\circledR}$ 


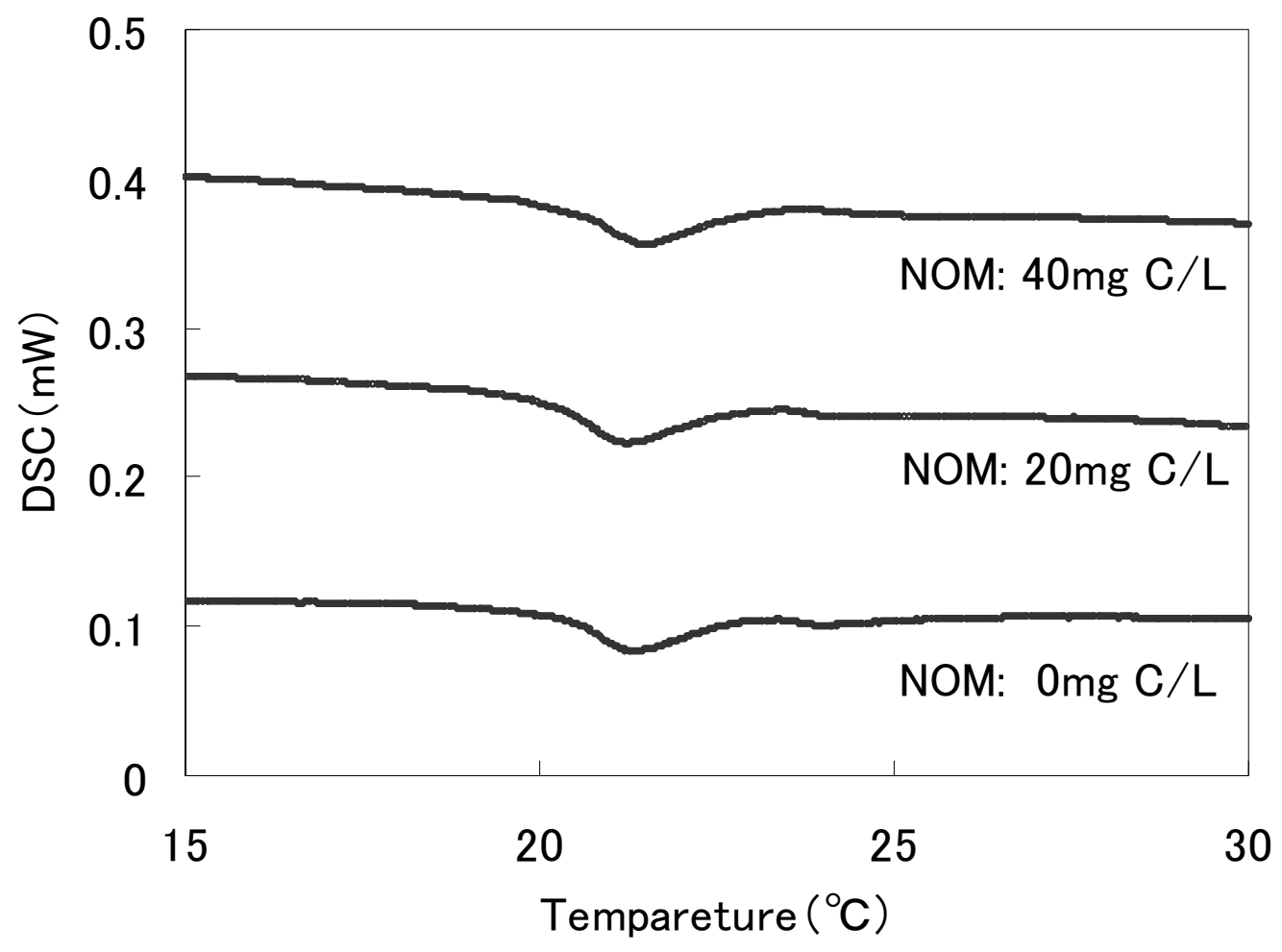

Fig.6 The effect of NOM on main phase transition temperature of DMPC-TRANSIL ${ }^{\circledR}$ membrane 